\title{
Effects of cimetidine and ranitidine on the pharmacokinetics of quinine
}

\author{
SOMPON WANWIMOLRUK ${ }^{1}$, METHI SUNBHANICH ${ }^{1}$, MALINEE PONGMARUTAI $^{1}$ \& \\ PISESPONG PATAMASUCON ${ }^{2}$ \\ ${ }^{1}$ Department of Pharmacology and ${ }^{2}$ Department of Pediatrics, Prince of Songkla University, Haad-Yai, \\ Thailand 90112
}

The pharmacokinetics of orally administered quinine were determined in six normal volunteers before and after a 7 -day course of cimetidine $\left(1 \mathrm{~g} \mathrm{day}^{-1}\right)$ or ranitidine $\left(300 \mathrm{mg} \mathrm{day}^{-1}\right)$. Peak plasma quinine concentration and the time of peak concentration were not altered after cimetidine or ranitidine pretreatment. After cimetidine pretreatment there was a significant reduction in the apparent oral clearance of quinine, from $0.182 \pm 0.063$ (mean \pm s.d.) to $0.133 \pm 0.0551 \mathrm{~h}^{-1} \mathrm{~kg}^{-1}(P<0.05)$. This was reflected in a $49 \%$ (range 17 to $90 \%)$ increase in the mean elimination half-life from $7.6 \pm 1.3$ to $11.3 \pm 3.7 \mathrm{~h}(P$ $<0.05)$. In contrast to cimetidine, ranitidine had no significant effect on the clearance or half-life of quinine. The apparent interaction between quinine and cimetidine may have therapeutic implications. Special care should be taken in patients taking these two common drugs concomitantly. Additionally, to avoid unnecessary risks due to drug interaction, the use of ranitidine may be preferable in the patients in whom it is desirable to administer an $\mathrm{H}_{2}$-receptor antagonist together with quinine.

Keywords quinine cimetidine ranitidine drug interaction pharmacokinetics

\section{Introduction}

Cimetidine has been shown to reduce liver blood flow and inhibit the metabolism of a number of drugs eliminated by the hepatic monooxygenase enzyme system (Gibaldi, 1984; Somogyi \& Gugler, 1982) which causes a decrease in the hepatic clearance of antipyrine, chlordiazepoxide, diazepam, phenytoin, theophylline, warfarin, lignocaine, and propranolol. Adverse effects resulting from interaction with cimetidine have been reported for those drugs with narrow therapeutic indices, such as warfarin and phenytoin. In contrast, the elimination of oxazepam, lorazepam and morphine (which occurs primarily via glucuronidation) are not affected by cimetidine. Ranitidine does not impair the metabolism of several drugs, including antipyrine, warfarin, propranolol, theophylline and phenytoin (Kirch et al., 1984).
Quinine is considered one of the drugs of choice for the treatment of acute attacks of malaria in areas such as Southeast Asia, South America and East Africa where Plasmodium falciparum is resistant to chloroquine (BruceChwatt, 1981; White, 1985; White et al., 1983). It is also the only available parenteral treatment for severe chloroquine-resistant malaria. Despite the fact that quinine is one of the oldest drugs in the pharmacopoeia and the most widely used antimalarial drug, there is relatively limited information on its pharmacokinetics and drug interactions (White, 1985). Studies in rats have shown that quinine is primarily metabolized by the liver to the hydroxy- and desmethylmetabolites (Barrow et al., 1980). In humans approximately $20 \%$ of an oral dose is excreted in the urine unchanged (Bruce-Chwatt, 1981; 
White, 1985; White et al., 1983). Its elimination half-life in healthy subjects and patients with falciparum malaria is highly variable ranging from 3.0 to $47.2 \mathrm{~h}$ (White, 1985). A mean plasma concentration of 2 to $5 \mathrm{mg} 1^{-1}$ is probably necessary to reduce parasitaemia in acute malaria and plasma concentrations above $10 \mathrm{mg}$ $1^{-1}$ are considered toxic (Bruce-Chwatt, 1981; White, 1985).

Since quinine is largely metabolized by hepatic microsomal oxidative biotransformation, a clinically important interaction between cimetidine and quinine could occur. The present study, therefore, investigated this possibility and compared the effect of cimetidine and ranitidine on the single dose pharmacokinetics of quinine in normal volunteers.

\section{Methods}

The study was approved by the Faculty of Science Ethics Committee, Prince of Songkla University.

\section{Subjects}

The subjects were six male volunteers, aged 29-43 years (weight $53-67 \mathrm{~kg}$, mean weight $59 \mathrm{~kg}$ ), who were healthy as determined by medical history, physical examination and standard biochemical and haematological parameters. Four of the volunteers are from a Chinese-Thai ethnic group and two of them are Thai according to their family history. No other drugs were taken in the month preceding the study nor during the study itself. Four subjects were smokers, each smoking 15-20 cigarettes daily. These same four subjects also drank an average of $250 \mathrm{ml}$ beer or $125 \mathrm{ml}$ of whisky per day prior to enrollment in the study. All subjects were asked to abstain from drinking alcoholic beverages during the course of the study.

\section{Protocol}

Each subject was studied on three occasions separated by at least 3 weeks. In a randomized fashion, subjects received no pretreatment or pretreatment with cimetidine (Tagamet, Smith Kline \& French Co., Thailand) $200 \mathrm{mg}$ three times a day (after meals) and $400 \mathrm{mg}$ at night or $150 \mathrm{mg}$ ranitidine (Zantac, Glaxo Ltd, Thailand) twice a day (after breakfast and dinner) for 1 week prior to quinine administration. Compliance to this pretreatment regimen was assured by tablet count. Volunteers fasted for $8 \mathrm{~h}$ before and $3 \mathrm{~h}$ after quinine administration. A cannula was inserted into a forearm vein for blood sampling and kept patent with heparinized saline (heparin, $5 \mathrm{u} \mathrm{ml}^{-1}$ ). An oral dose of $600 \mathrm{mg}$ quinine sulphate (497 mg quinine base) was administered between 08.00 and $09.00 \mathrm{~h}$ to each subject with approximately $100 \mathrm{ml}$ of water. Cimetidine or ranitidine were also administered just prior to quinine administration and then continued with the regimen described above until the last blood sample was obtained. Venous blood samples $(6 \mathrm{ml})$ were obtained before and at $0.25,0.50,0.75,1,1.5,2,2.5,3,4,6,8,10,12$, 24 and $30 \mathrm{~h}$ post-dose. Plasma was separated by centrifugation within $2 \mathrm{~h}$ and stored at $-20^{\circ} \mathrm{C}$ until assayed.

\section{Analytical procedures}

Quinine plasma concentrations were determined by a modification of the spectrophotofluorometric assay (Greenblatt et al., 1977). Plasma $(0.5 \mathrm{ml})$ was mixed with $0.5 \mathrm{ml}$ of $0.1 \mathrm{~N}$ $\mathrm{NaOH}$. Redistilled toluene $(5 \mathrm{ml})$ and isoamyl alcohol $(0.2 \mathrm{ml})$ were then added, and the mixture was shaken vigorously for $1 \mathrm{~min}$. After centrifugation at $2000 \mathrm{rev} \mathrm{min}^{-1}$ for $5 \mathrm{~min}, 3 \mathrm{ml}$ of the organic phase was transferred to another tube containing $3 \mathrm{ml}$ of $0.1 \mathrm{~N} \mathrm{H}_{2} \mathrm{SO}_{4}$. This was shaken for $1 \mathrm{~min}$ and centrifuged. The organic layer was aspirated and discarded. The fluorescence of the acid extract was then determined at $350 \mathrm{~nm}$ excitation and $450 \mathrm{~nm}$ emission using a Perkin-Elmer MP-3000 fluorescence spectrometer. Appropriate standards were prepared in distilled water and a blank was analysed with the study samples. Preliminary experiments in our laboratory indicated that analysis of quinine in plasma or water yielded identical standard curves. Inter-assay variation between standards did not exceed $3 \%$. In all assays the intra-assay coefficients of variation were less than $5 \%$. The double-extraction fluorometric assay used in this study gives identical results for quinine and the diastereoisomer quinidine. Dihydroquinine and dihydroquinidine are quantitated in this method, but the polar metabolites (hydroxy- and $O$ desmethyl-) are largely excluded (Vasiliades \& Finkel, 1983). This method gives results comparable to more specific methods including gasliquid chromatography (GC), GC combined with mass spectroscopy, and high performance liquid chromatography. The slopes of the method-comparison regression lines were usually 0.9 or higher (Ochs et al., 1980; Vasiliades \& Finkel, 1983). Neither cimetidine nor ranitidine interfered with the fluorometric assay of quinine.

\section{Analysis of results}

The following pharmacokinetic parameters 
were estimated from the plasma quinine concentration-time profiles in each individual study. Apparent first-order elimination rate constant $\left(k_{\mathrm{e}}\right)$ was calculated by linear leastsquares regression analysis of the terminal phase of the plasma concentration-time profile. Area under the plasma concentration-time curve from zero to infinity time (AUC) was calculated by the trapezoidal rule from the beginning of the drug administration to the last data point and with extrapolation to infinity. The area from the last data point $\left(C_{t}\right)$ to infinity was obtained as $C_{\mathrm{t}} / k_{\mathrm{e}}$. The apparent oral clearance (CL) was estimated, assuming i) complete bioavailability of quinine and ii) the $\mathrm{H}_{2}$-receptor antagonists do not alter the bioavailability, according to the relationship.

$$
\mathrm{CL}=\mathrm{Dose} / \mathrm{AUC}
$$

Elimination half-life $\left(t_{1 / 2}\right)$ was calculated as $0.693 / k_{\mathrm{e}}$. Since sampling around the peak was frequent, the highest value in the plasma concentration profile was assumed to represent the peak concentration $\left(C_{\max }\right)$. The time to reach this peak concentration was denoted as $t_{\max }$.

Results are expressed as mean \pm s.d. The significance of differences between study phases was assessed using ANOVA with repeated measures (Zar, 1984) followed by the NewmanKeuls test where appropriate. Bartlett's test was used to assess homogeneity of variances. Values of $P>0.05$ were regarded as not significant (NS).

\section{Results}

Figure 1 shows the mean concentration-time profile for plasma quinine, with and without cimetidine or rantitidine pretreatment in the six subjects. The pharmacokinetic data are summarized in Table 1. Cimetidine and ranitidine did not alter $C_{\max }$ or $t_{\max }(P>0.5)$, and the quinine concentrations on the up-curve of the plasma concentration-time profiles were not significantly different, suggesting that these two $\mathbf{H}_{2}$-receptor antagonists may not alter quinine absorption kinetics. In all subjects co-administration of cimetidine caused a significant increase in $t_{1 / 2}$ of quinine. The mean $t_{1 / 2}$ increased by $49 \%$ (range $17-90 \%$ ). For each subject, the AUC was greater after pretreatment with cimetidine $(P<0.05)$. This resulted in a significant decrease in mean apparent oral clearance of $27 \%$ (range $18-42 \%$ ) from $0.182 \pm 0.063$ to $0.133 \pm 0.0551 \mathrm{~h}^{-1} \mathrm{~kg}^{-1}$.

In contrast, ranitidine pretreatment did not produce a significant change in the mean $t_{1 / 2}$ of quinine (Table 1) as compared to the control (quinine alone). After pretreatment with ranitidine, the mean $t_{1 / 2}$ of quinine was slightly longer, but the change was not significant. The mean $t_{1 / 2}$ of quinine after ranitidine pretreatment was also

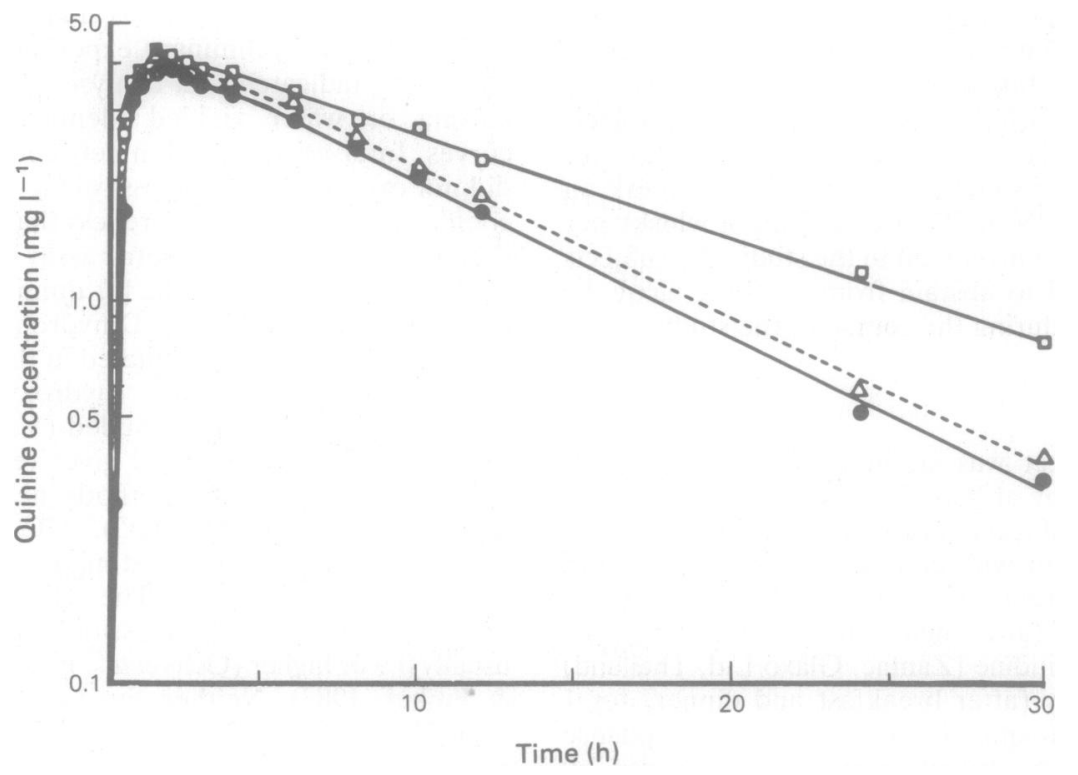

Figure 1 Mean plasma concentration of quinine following a single oral dose of $600 \mathrm{mg}$ of quinine sulphate (•), and after co-administration of quinine with either cimetidine, $1 \mathrm{~g}$ daily for 7 days () or ranitidine, $300 \mathrm{mg}$ daily for 7 days $(\Delta)$ in six healthy volunteers. 
Table 1 Comparison of the effects of cimetidine and ranitidine on the pharmacokinetic parameters of quinine in six normal volunteers (mean \pm s.d.)

\begin{tabular}{lcccl}
\hline Parameter & Control & $\begin{array}{c}\text { After } \\
\text { cimetidine }\end{array}$ & $\begin{array}{c}\text { After } \\
\text { ranitidine }\end{array}$ & ANOVA \\
\hline$C_{\max }\left(\mathrm{mg} \mathrm{1}^{-1}\right)$ & $4.3 \pm 0.9$ & $4.4 \pm 1.0$ & $4.5 \pm 1.4$ & NS \\
$t_{\max }(\mathrm{h})$ & $1.5 \pm 0.7$ & $1.6 \pm 0.4$ & $1.6 \pm 0.8$ & NS \\
$t_{1 / 2}(\mathrm{~h})$ & $7.6 \pm 1.3^{*}$ & $11.3 \pm 3.7^{* \dagger}$ & $8.6 \pm 2.5 \dagger$ & $P<0.005$ \\
AUC $\left(\mathrm{mg}^{-1} \mathrm{~h}\right)$ & $53.9 \pm 16.9^{*}$ & $76.8 \pm 32.3^{*}$ & $64.9 \pm 28.5$ & $P<0.05$ \\
$\begin{array}{l}\text { Apparent oral clearance } \\
\quad\left(1 \mathrm{~h}^{-1} \mathrm{~kg}^{-1}\right)\end{array}$ & $0.182 \pm 0.063^{*}$ & $0.133 \pm 0.055^{*}$ & $0.168 \pm 0.093$ & $P<0.05$ \\
\hline
\end{tabular}

${ }^{1}$ Treatment effects on quinine pharmacokinetic parameters were detected by analysis of variance (ANOVA) with repeated measures (Zar, 1984). Values bearing the same superscript symbol $\left({ }^{*}\right.$ or $\left.\dagger\right)$ were judged to be different $(P<0.05)$ by the Newman-Keuls test.

significantly shorter $(P<0.05)$ than that observed after cimetidine pretreatment. Overall, the mean AUC and mean apparent oral clearance of quinine in the ranitidine treatment period were not significantly different from the control. The six subjects showed an intersubject variation in the AUC values ranging from a value of $75 \%$ to $145 \%$ of their control value. However, the magnitude of increase in AUC during ranitidine treatment in some subjects was consistently less than that observed during cimetidine treatment. The mean apparent oral clearance during ranitidine treatment period was greater than that during the cimetidine treatment but this just failed to be significant.

\section{Discussion}

The results of this report show a rapid absorption of quinine in healthy men (Figure 1). Values for $C_{\max }$ and $t_{\max }$ are comparable to those reported by Garnham et al. (1976). The $t_{1 / 2}$ ranged from 6.3 to $9.6 \mathrm{~h}$ with a mean of $7.6 \pm 1.3 \mathrm{~h}$ which is similar to that reported by Trenholme et al. (1976), but it is shorter than that reported by White et al. (1983). The apparent clearance of quinine found in our study is less than that for its diastereoisomer quinidine (Hardy et al., 1983; Kolb et al., 1984; Ochs et al., 1980). There was considerable interindividual variation in the apparent oral clearance of quinine in the six male subjects studied as reflected by a high coefficient of variation (35\%, Table 1$)$. This may be due to genetic influences and differences in environmental factors such as diet; smoking, chemical exposure; coffee and alcohol consumption, etc. (Gibaldi, 1984; Vesell \& Penno, 1983).

Kolb et al. (1984) found no change in the $C_{\max }$ and $t_{\max }$ values of quinidine after cimetidine treatment. These results are similar to our data which show no effect on these parameters of quinine. However, Hardy et al. (1983) reported higher $C_{\max }$ values of quinidine and a delay in $t_{\max }$ after cimetidine treatment. They suggested that these effects may be related to hepatic enzyme inhibition, reduced liver blood flow, or both, due to cimetidine treatment.

The present study shows that the usual therapeutic regimens of cimetidine decrease quinine clearance and prolong the $t_{1 / 2}$ of quinine. Activity of drug metabolizing enzymes is considered to be one of the major determinants of the elimination of low clearance drugs (Rowland et al., 1973; Wilkinson \& Shand, 1975). Low clearance drugs are relatively insensitive to changes in hepatic blood flow. Quinine is considered a low clearance drug. This view is supported by our study where the mean apparent oral clearance of quinine which reflects the total intrinsic capacity of liver enzymes to metabolize the drug, was $10.0 \pm 3.21 \mathrm{~h}^{-1}\left(0.182 \pm 0.0631 \mathrm{~h}^{-1} \mathrm{~kg}^{-1}\right)$ and is also supported by previous data (White $e t$ al., 1983) reporting the mean total clearance of $6.91 \mathrm{~h}^{-1}$ (based on a body weight of $60 \mathrm{~kg}$ ). Thus a reduction in the clearance of quinine during the treatment of cimetidine found in this study would be due to inhibition of the hepatic mixed-function oxidase system by cimetidine. This effect of cimetidine on the elimination of quinine is quantitatively similar to that occurring with quinidine (Farringer et al., 1984; Hardy et al., 1983; Kolb et al., 1984). In contrast, ranitidine pretreatment did not cause significant changes in the pharmacokinetic parameters of quinine indicating that in agreement with previous reports (Kirch et al., 1984), ranitidine does not significantly inhibit drug metabolism.

In conclusion, in healthy men, co-administration of quinine and cimetidine induced a significant fall in mean apparent oral clearance of quinine, while ranitidine had no significant effect. The interaction between quinine and cimetidine may 
have therapeutic implications and in particular indicate that special care should be taken in patients taking these two common drugs concomitantly. Because in general clinical practice, routine therapeutic concentrations of quinine are not monitored, ranitidine may be a more suitable $\mathrm{H}_{2}$-receptor antagonist for patients with malaria receiving quinine in order to avoid unnecessary risks due to drug interaction.

This study was supported by grants from the National Research Council of Thailand and from Glaxo (Thailand) Ltd. and was presented in part at the meeting of the Southeast Asian and Pacific Region Society of Pharmacologists, Penang, Malaysia, May 1985.

\section{References}

Barrow, S. E. Taylor, A. A., Horning, E. C. \& Horning, M. G. (1980). High-performance liquid chromatographic separation and isolation of quinidine and quinine metabolites in rat. J. Chromatogr., 181, 219-226.

Bruce-Chwatt, L. J. (1981). Chemotherapy of malaria . 2nd edn., Geneva: WHO.

Farringer, J. A. McWay-Hess, K. \& Clementi, W. A. (1984). Cimetidine-quinidine interaction. Clin. Pharm., 3, 81-83.

Garnham, J. C., Raymond, K., Shotton, E. \& Turner, P. (1976). The bioavailability of quinine. Am. J. Trop. Med. Hyg., 70, 264-269.

Gibaldi, M. (1984). Biopharmaceutics and clinical pharmacokinetics. 3rd edn., pp. 257-285. Philadelphia: Lea \& Febiger.

Greenblatt, D. J., Pfeifer, H. J., Ochs, H. R., Franke, K., MacLaughlin, D. S. Smith, T. W. \& KochWeser, J. (1977). Pharmacokinetics of quinidine in humans after intravenous, intramuscular and oral administration. J. Pharmac. exp. Ther., 202, 365-378.

Hardy, B. G., Zador, I. T., Golden, L., Lalka, D. \& Schentag, J. J. (1983). Effect of cimetidine on the pharmacokinetics and pharmacodynamics of quinidine. Am. J. Cardiol., 52, 172-175.

Kirch, W., Hoensch, H. \& Janisch, H. D. (1984). Interactions and non-interactions with ranitidine. Clin. Pharmacokin., 9, 493-510.

Kolb, K. W., Garnett, W. R., Small, R. E., Vetrovec, G. W., Kline, B. J. \& Fox, T. (1984). Effect of cimetidine on quinidine clearance. Therap. Drug Monit., 6, 306-312.

Ochs, H. R., Greenblatt, D. J., \& Woo, E. (1980). Clinical pharmacokinetics of quinidine. Clin. Pharmacokin., 5, 150-168.
The authors are indebted to Professor D. J. Birkett, Department of Clinical Pharmacology, Flinders Medical Centre, Australia, for his excellent advice and for being a consultant for this work. We thank $\mathrm{Dr}$ R. W. Scott, School of Pharmacy, State University of New York at Buffalo, for his valuable discussion. Grateful thanks are due to Professor Danai Bunnag, Faculty of Tropical Medicine, Mahidol University, Bangkok, Thailand, for being the consultant on this project and to Miss Rattana Janjareontham for her competent technical assistance in the insertion of indwelling cannulas.

Rowland, M., Benet, L. Z. \& Graham, G. G. (1973). Clearance concepts in pharmacokinetics. $J$. Pharmacokin. Biopharm., 1, 123-136.

Somogyi, A. \& Gugler, R. (1982). Drug interactions with cimetidine. Clin. Pharmacokin., 7, 23-41.

Trenholme, G. M., Williams, R. L., Reickmann, K. H., Frischer, H. \& Carson, P. E. (1976). Quinine disposition during malaria and during induced-fever. Clin. Pharmac. Ther., 19, 459-467.

Vasiliades, J. \& Finkel, J. M. (1983). Determination of quinidine in serum by spectrofluorometry, liquid chromatography and fluorescence scanning thin-layer chromatography. J. Chromatogr., 278, 117-132.

Vesell, E. S. \& Penno, M. B. (1983). Assessment of methods to identify sources of interindividual pharmacokinetic variations. Clin. Pharmacokin., $8,378-409$.

White, N. J. (1985). Clinical pharmacokinetics of antimalarial drugs. Clin. Pharmacokin., 10, 187-215.

White, N. J., Chanthavanich, P., Krishna, S., Bunch, C. \& Silamut, K. (1983). Quinine disposition kinetics. Br. J. clin. Pharmac., 16, 399-403.

Wilkinson, G. R. \& Shand, D. G. (1975). A physiological approach to hepatic drug clearance. Clin. Pharmac. Ther., 18, 377-390.

Zar, J. H. (1984). Biostatistical analysis, 2nd edn., pp. 190-191; pp. 222-226. Englewood Cliffs, New Jersey: Prentice-Hall, Inc.

(Received 4 April 1986, accepted 28 May 1986) 